\title{
Moral Qualification in Business Communication
}

\author{
Amrendra Kumar $\operatorname{Singh}^{1} \&$ Nirbhay Mishra ${ }^{2}$ \\ ${ }^{1}$ Applied Sciences \& Humanities, NIIT University, Neemrana, India \\ ${ }^{2}$ Institute of Applied Sciences \& Humanities, GLA University, Mathura, India \\ Correspondence: Amrendra Kumar Singh, Applied Sciences \& Humanities, NIIT University, Neemrana, India. \\ E-mail: amrendra.singh@niituniversity.in
}

Received: October 9, 2012 Accepted: March 4, 2013 Online Published: March 13, 2013

doi:10.5539/ijbm.v8n8p1 URL: http://dx.doi.org/10.5539/ijbm.v8n8p1

\begin{abstract}
The present paper offers a moral discourse on the idea of business communication. The role of communication in business is undoubtedly pivotal; however, the competent communication is the key that opens the doors of solidarity and successes for business. Business professionals have to qualify both the Business Linguistic as well as Moral Fitness conditions so as to develop the sense of language and finally evolve as a competent communicator. It advocates the position of Moral Fitness as well in formal communication where the communicator has the responsibility to deal with as many social variables.
\end{abstract}

Keywords: business linguistic, linguistic experience, linguistic psyche, collective moral space, corporate epistemic structure, corporate moral personality

\section{Introduction}

Considering businesses as social institutions (Cody, 2006: Freeman 2002; Petit, 2007), we aim to offer a moral discourse on the idea of business communication. In recent times business communication has occupied a center stage for many who view this concept as linchpin in making businesses a successful social enterprise. The role of communication in business is undoubtedly pivotal; however, the competent communication is the key that opens the doors of solidarity and successes for business. Business processes include various communicative actions for meeting the needs of business. Business professionals, in their routine business life, have to communicate not only with the line and staff management but also to those who are reckoned as stakeholders. Whether it is about the inter business contexts or the intra business contexts, business professionals have to be doubly qualified: 1) Satisfying the Business Linguistic (hereafter, BL) conditions, and 2) Satisfying the Moral Fitness conditions. The paper by thoroughly researching the idea of business communication, proposes a moral perspective on business communication. Business linguistics is in its very ordinary sense means performing language in a scientific manner by having recourse to The Sense of Language (hereafter, $\mathrm{SOL}$ ) that underlies socio-cultural rationality and background intentionality. In SOL what we are discussing is one step ahead to having just the grammatical understanding of language. We take SOL as a matter of competent communication insofar as it differs from the just communication in a sense that a communicative action performed by a business professional, despite alright grammatically, may be disqualified if it does not take into account business linguistic and moral affairs in addressing the business matters and issues. Taking communication as basic we construe competent communication as a benchmark for business communication.

The design of the paper is as such that we begin with explaining the idea of business communication and then move on to understand the concept of, what we call, SOL. Further, we define SOL by explaining the BL. In offering an explanation of BL we develop arguments from the structuration of language underpinning the socio-cultural and psycho-anthropological understanding of language. At this juncture, we argue from the viewpoints of linguistic experience and language psyche. Establishing the satisfaction conditions for business linguistic, thereafter, we address to what we call the moral fitness conditions for competent business communication. Keeping the present international business scenario upfront we emphasize the significance of moral relativism in business life in the global context. Business professionals, performing the communicative actions, in international business situations in the multi-cultural global context, have to be rational and intentional actors in order to qualify the moral fitness conditions. Being rationally moral here means adopting the business linguistic stance (understanding the moral reasons by having recourse to the SOL) and being intentional 
refers to the background against the business communication is being performed. Here the moral fitness conditions though follow the routes of moral philosophy and theories of responsibility, however, are more developed than just having the knowledge and control over actions. We end up with this that a competent business communication presupposes both business linguistics and moral fitness in the priority order.

\section{Business Linguistics}

To have the basic generalized patterns of human communication system, we start with the model, as suggested by Kelkar (1980). It is very important here to understand the very idea of Business Linguistic (BL), supplemented and shaped by Linguistic Experience and Psyche (LE \& LP), recommends and forms the nature of Sense of Language ( $S O L$ ). The basic structure of the argument as follows:

$$
* \mathrm{BL}(\mathrm{LE} \& \mathrm{LP})>\mathrm{SOL}>\mathrm{CC}
$$

We think that the model initiates a very close picture of the existence of human beings and their participation in a communicative event. The study suggests an interaction between the universe and an organism, located spatio-temporally in the universe. The organism is an organism to the extent it maintains an internal systemic coherence. This internal maintenance in turn depends at least partly or an interaction with the rest of the universe - at least, with its immediate space-time neighborhood. In the context of this paper, it suggests that the communicator has to maintain coherence with the environment which entails his/her successful survival in different contexts, (e.g. corporate, social, personal, institutional, organizational etc.) where an individual experience a whole different sequences of events which determines their corresponding behaviors. The model is basically formed as:

E-events.......... (S-events (Experience), I-events (Personalized) and A-events (Behavior)) - [ An organism's experience \& behavior in space-time].........E-events

These events shape the nature of S-events which further determines the nature of one's experience. I- event (personal realization or the personalized experience) results in the respective behavior or the response manifested by the individual. Now when an individual participate in a social interaction, it adds new meaning to the harmonious interaction with the environment. Not only this, the S-I-I-A or I-I-I event sequences proposes the internal experience which further motivated or reflected in different experiences over the period of time with respect of maturational processes. While talking about the social interaction, it becomes obvious to refer culture which shapes and supplement any social interaction. It is the culture that determines the nature of the context in social interaction. In prolegomena, Kelkar suggests the nature of cultural underpinnings which forms the basis of routines in social interaction. The routines means to suggest the regularity of events which further acts as a catalyst to form the nature of shared practices.

i. The greater the cohesion of the social envelope the greater the overall sharing of routines (experience routines, behavior routines) of similar and/or coordinated experience and behavior.

ii. This overall sharing of routines creates a shared structuring and recognition of routines in experience, behavior, and semiosis (p. 26).

Here the shared structuring and recognition intends experience and behavior which are predominantly guided by culture specific norms. These are the life-promoting routines; deviation from the same would result in life-harming or a sort of mis-adjustment in a social interaction. We shall not attempt to get into a detailed explanation of the semiotics of communicative event. To stick to the basic temperament of the paper, our concern is more circumspect here - we see business set up as a cultural as well as a different and separate sequence of events, highly motivated and governed by specific experience, resulted in different modes of behavior altogether. Business linguistics signifies the complex of events occur in a specific social interaction which also result in certain specific behavioral practice. This practice, further, is motivated by certain linguistic features, shaped by shared features of a particular community/group/environment. The participants of the same community result in shared behavioral traits and the organization also behave or respond in a particular way - motivated by the shared features of the group.

Our idea of business linguistic refers to a different form of language behavior which is not at all context free, but context bound. It is the context which shapes the nature as well as the form of language used in any communicative action. Words themselves have little meaning until placed in the context of culture, relationships, and people. In low-context culture, the communicators do not assume a great deal of shared, collective knowledge rather the content level of meaning is given priority. On the other hand, in high-context culture the content meaning of the words play less significant role than the assumed collective knowledge. For example, in a low-context culture, a person might say to a coworker, "Let's get together to talk about our project. We can 
meet in my office at 2 today and you can bring the draft. I'll order some coffee for us." In high-context culture, the message might be "Let's meet at 2 to discuss our project." In the low-context culture, the communicator assumes that the coworker will share cultural understandings about where to meet, what to bring, and whether there will be a beverage (Lim, 2002). Scholars have identified three dimensions of relationship-level meanings; the first is the responsiveness (it refers to how aware of others and involved with them we are), the second, is the liking or affection (the degree of positive and negative feeling), and the third is power balance between communicators. What we mean by these meanings as the extensional or suggestive meanings which do not directly determine the nature of content meaning but they do determine the selective choices of the same used in various distinct contexts.

When the National Association of Colleges and Employers asked 480 colleges what applicant qualities and abilities were most important to them in making hiring decisions, communication skills were at the top of the list (Schneider, 1990). According to the employers, effective job performance depends critically on skills such as expressing oneself clearly, listening well to others, creating productive working environment, and being sensitive to differences in how people perceive communication. Here, what are the communications skills required to perform so as to earn the status of competent communicator? The characteristic of 'expressing oneself clearly' does not mean to convey the grammatical encoding in any language as such, rather it warrants for the expected supplement of the linguistic experience that would determine the form as well as the nature of the same grammatical encoding. In India, the so called corporate culture is taught/trained (or the so is popular in the Asian or in other countries with various ethnicities) because of the difference in the sequences of events aligned with different linguistic experience which result in the mismatch of the manifested behavior per se. Now we move on to realize how linguistic experience and psyche play a significant role in forming the concept of Business Linguistic.

\subsection{Linguistic Experience and Psyche}

Blomberg (1997) establishes a link between interpersonal and intrapersonal communication. The established sign-symbol-code system operates in our daily lives which exist in our interpersonal relationships. This has been termed as 'relational culture' (Wood, 1995). These relational cultures are created and maintained a complicated interconnectedness of the sign-symbol-code systems of the two partners. Through this process, these relationships are defined and normalized, creating a relational identity for the partners. In this process, relational identity moderates individual's role in negotiation and manipulation of the partners. When intrapersonal meanings are shared effectively interpersonally, relationships function in a special and fulfilling way. Altman and Taylor (1973) have identified the characteristics that are present in relationships that successfully blend intrapersonal meanings and interpersonal meanings; some of these are: richness, efficiency, uniqueness and substitutability. These characteristics again in turn do not suggest any concrete form as such. Broadly speaking, these characteristics are the marked features to conduct a smooth or healthy communication.

When Tannen (2000) suggests the communication patterns between couples, highly moderated by too many unspoken patterns, which finally causes disturbances, or to say, severe breakdown in the scope of whole communication process. In this case, the richness, uniqueness, efficiency or the substitutability of the closed partners becomes ineffective to serve the very purpose of their relationship. What we mean by linguistic experience is the common sequential events within a group of people or in a community. And psyche determines the varying individual's responses to the same experience. In the above case, it is the same linguistic experience of the events that enable the two partners to stay together and participate in any communicative act. But the psyche creates the difference in their communicative pattern; one may call it gender, class, societal etc. difference. One may find it as the physiological factors that affect the nature of communicative action. For instance, "The power of naming is dramatically clear in the case of Rose Marie Augustine, a resident of Tucson, Arizona. For years, Augustine had tried to get local officials to recognize that polluted wells in her community were making residents ill, but officials refused to acknowledge that there was a problem. At a meeting of environmentalists, Augustine heard language that named the problem. She said, "I heard words like 'economic blackmail', 'environmental racism'. Somebody put words, names, on what our community was experiencing" (in Cox, 2006). It can be inferred that the people of the same community have different expressions for the same experience. This is what shapes the linguistic experience which is further modulated by individual's psyche that has very much internal coherence in the system. Imagine the scenario: An American businessman travels to japan to negotiate a deal. After the American has made his proposal, the Japanese businessman responds, "I see you have put much thought into this idea". Assuming that this indicates Japanese executive is pleased with the proposal, the American says, "So, shall we sign the contract and be on our way?" The Japanese executive replies, "I think we have much to discuss about your good proposal." What is important here is the way communication 
takes place. It is both their difference in the experience of sequence of events that is further manifested in their overall communication pattern. If we consider 'business' broadly as a domain of life, it suggest certain sequence of events which is very much explicit in their statements. The distinctive feature of politeness is the basic difference here. And this difference is acquired as a routinized feature. Politeness, Affection, Care, and Concern so on and so forth are the routinized features of communicative behavior which are called linguistic experience. Now, these experiences are practically realized unless appropriate psyche forms the basis of it. In the United States, saying 'good-bye' to guests is a matter of single event. In contrast, in Japan saying 'good-bye' refers to a process. It starts in the living room and lasts till there is any substantial distance occurs between the host and guests. Here also, it is the linguistic experience of saying 'good-bye' to anyone is differently perceived in two different events (US \& Japan). Now the same 'good-bye' will have conditioned realizations while being used in Japanese culture. Here the realizations will have varying forms, depending on individual's psyche which determines the presentation of the same in given contexts.

Both linguistic experience as well as psyche contributes to the formation of Business Linguistic that typically refers to a specific context of Business. Langsdorf (1994) talks about 'critical-cultural approach' where 'interpretation' plays a vital role in getting two people understand each other's experiences. This gives the scope for uncovering the possible meanings. Further he talks about the possible interpretations as Texts and relationships as Context (The background of the communication). The way text and the context are related to each other determines the reflexivity. When the text and the context confirm each other, this is called a charmed link. To achieve this 'charmed link', what we suggest here is that there has to be a perfect harmony of linguistic experience and psyche. Once linguistic experience is perceived well, the possible interpretations can be managed within the given choices. It is somewhere guided by the linguistic psyche (neuro-physiological alterations) which determines the nature of possible meanings to the expressions. Linguistic experience is centered on subjective experience of the events in a sequence but the psyche is the affect caused on the speaker due to this when he/she participates in a communicative action. Linguistic psyche is generally realized by the hearer who assess and determines the objectivity of the encoded expressions. In the present business scenario, all efforts are invested in marking the cultural differences, so the next section will discuss differences in culture across.

However, culture plays a significant role in assigning the surface attributes to the meaning of a word which is further realized in terms of extensional meanings of the same. For example, Hopi Indians have one word for "water in open space" and another word for "water in a container" whereas the English language has only the noun, water. The assigned meaning has a form which is realized in different extensional forms. These forms advance different linguistic experiences, depending on the individual's experience, beliefs, values etc. These linguistic experiences guide or regulate the responses of the hearer, participating in a communication process.

\subsection{Culture Relativism}

In order to explain a bit further, we need to see the cultural variation results in various forms in the society. In today's world, popular terms such school culture, college culture, corporate culture, government office culture etc. have been succeeded in creating some distinct images in our minds. Business linguistics has a definite reflection of cultural relativism in corporate culture which is observed in the new trends of cultural training/adjustment organized frequently. Cultural relativism has been used to see the different marked features which allow different identities to relate and mark differences sometimes in appositions and sometimes with inappositions. The distinctive human way of life that we call culture did not have a single definite beginning in time any more than human beings suddenly appearing on earth. Culture evolved slowly just as some anthropoids gradually took on more human form.

The concept of culture was rigorously defined by E.B. Taylor in 1860s. According to him culture is the sum total of ideas, beliefs, values, material cultural equipment and non-material aspects which man makes as a member of society. Taylor's theme that culture is a result of human collectivity has been accepted by most anthropologists. Taylorian idea can be discerned in a modern definition of culture - culture is the man-made part of environment (M.J. Herskovits).

From this, it follows that culture and society are separable only at the analytical level: at the actual existential level, they can be understood as the two sides of the same coin. Culture, on one hand, is an outcome of society and, on the other hand, society is able to survive and perpetuate itself because of the existence of culture. Culture is an ally of man in the sense that it enhances man's adaptability to nature. It is because of the adaptive value of culture that Herskovits states that culture is a screen between man and nature. For instance, in showing affection, the Maori rub noses; the Australians rub faces; the Chinese place nose to cheeks; the Westerners kiss; some groups practice spitting on the beloved. Or, consider this; American men are permitted to laugh in public 
but not to cry; Iroquois men are permitted to do neither in public; Italian men are permitted to do both. Since this is true, physiological factors have little to do with when men laugh and cry and when they do not do either. The variability of the human experience simply cannot be explained by making reference to human biology, or to the climate and geography. Instead, we must consider culture as the fabric of human society.

What we can observe here is that culture is conceived as a continuous, cumulative reservoir containing both material and non-material elements that are socially transmitted from generation to generation. Culture is continuous because cultural patterns transcend years, reappearing in successive generations. It is cumulative because each generation contributes to the reservoir. It is somewhere not easy to mark the contribution paradigmatically at micro level but it can be marked, of course syntagmatically, as a successive development. An inherent paradox exists within the social heritage where culture tends to be both static and dynamic. Humans, once having internalized culture, attach positive value judgments to it and are more or less reluctant to change their established ways of life. Through most of recorded history men have apparently considered that change per say is undesirable and that the ideal condition is stability. The prospect of change can seem threatening, yet every human culture is subject to and does experience change (though we can witness the same when cultural organizations do react in the name of maintaining stability in the practice, belief etc.). We do acknowledge the change in terms of generation gap, cultural adjustment and so on. Well, the reflection of culture can be perceived in all sphere of human existence. To serve the objective of the paper, we will stick to the relationship between human communication and culture.

We have become conditioned, perhaps culturally or inter-culturally, to think in terms of one-to-one relationship between our language system and so-called world. However the linguistic structures depend on the verbal signals which are never the exact representations of the things they stand for. Any human being is a product of feelings, emotions, attitudes, neural messages, circulatory systems, brain waves and cellular structures. And these components are never words. Since all verbal or non-verbal signals are motivated by silent presuppositions which is finally reflected in the system. Wendall's (1972) 'undefined terms' refers to the state when an individual misses out the exact word for a concept or a thing. It refers to one's helplessness towards communicating the exact idea which results in different behavioral or physiological changes in his/her temperament. Since the human communication system is designed in a way to encode the verbal as well as non-verbal signals which are shared by a group of people then we do have to see the factors responsible to shape these signals.

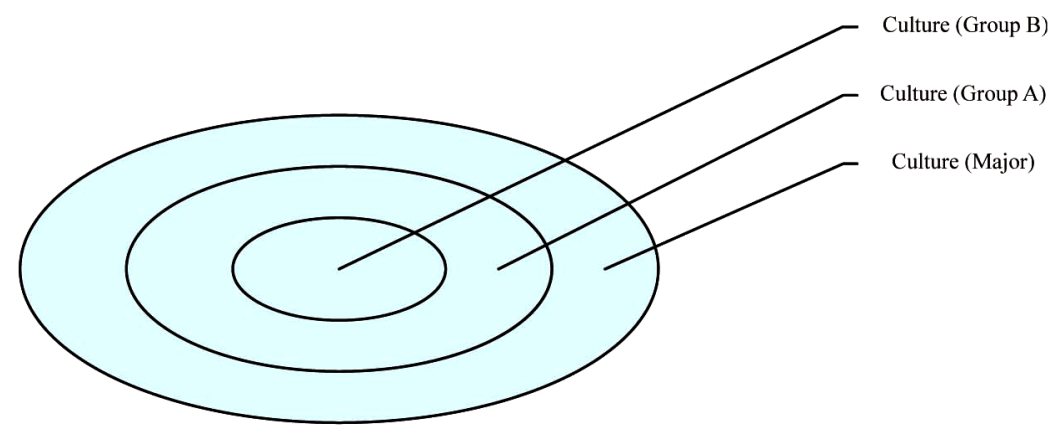

Figure 1. Cultural setting

In the above fig. 2, it can be seen that the small groups contribute to the characteristics of the cultural identity formation of the relatively the largest group where the core is considered as the deep culture that is common to all the other bigger groups. The biggest group emerges out of all will have the shared features of all the smaller groups along with its own specific features which are not necessarily present in the sub groups. Each smaller group will have their respective unique features which contribute to the distinct identity of each sub groups. Now the encoding will vary depending on the unique features of the group. But the commonality helps in bridging the gap wherever required that further encourages the whole communication process to take place comfortably to the extent possible (to the extent breakdown does not occur).

In the recent communication network, Hayakawa's (1949) statement still holds its relevance,

If you say, 'This table measures six feet in length,' you can prove it by taking a foot rule, performing the operation of laying it end to end while counting, 'One....two....three...four....' But if you say, '.....Man is born free, but everywhere he is in chains!'---what operations could you perform to demonstrate its accuracy or 
inaccuracy?

Hayakawa speaks of a hiring official who discards an application form when he comes upon the note: "Education: Harvard." It automatically entails that the hiring officer is not fond of applicants from Harvard. It means that the word not only symbolizes the meaning but also the inherent capacities which finally reflected in different actions or motivations in the hearers. It carries not only the ascribed meaning but also the extensional possible meanings that get shape in different social settings and further in different individuals who are governed by his/her personal sense of judgment (as far as individual's choices are concerned). Johnson (1972) identifies it as humans' strive to make communication as operational as possible and suggest strategies to make the communication more effective: Indexing (to put people into convenient groups depending upon their abilities, peculiarities, physical characteristics etc.), Dating (awareness of time), Intentional -Extensional (The conceptthe word symbolizes reality in a real sense), Facts $>$ Inference $>$ Judgment. Here, it does try to explain the basic principles of communication process but does not prescribe moral fitness condition, linguistic experience and linguistic psyche which regulate and moderate the communication channel completely.

Since communication is irreversible in its nature does affect others, it always has ethical implications. What we say and do affects others: how they feel, how they perceive themselves, how they think about themselves, and how they think about others. Thus, responsible people think carefully about ethical guidelines for communication. For instance, should you not tell someone something that might make him less willing to do what you want? In personal lives, one may react in various possible ways but in work setting, one avoids giving negative feedback because it hurt others' feelings. These are the conditions which add on ethical choices to the possible expressions though they satisfy the necessary conditions of BL $>$ SOL. What we argue here is the necessary condition of SOL is required to evolve as a competent communicator. We believe that sense of language, literally mean the use of language in context, are not visualized ambitiously so as mean the use of language supplemented with whole background as well as intentionality. The next section further elucidates the ethical form of fitting business communication.

\section{Moral Fitness Condition}

A business professional having the business linguistic sense does not guaranty that $\mathrm{s} / \mathrm{he}$ would perform business communication effectively. Indeed as we have been argued that it is business linguistic sense that has to have a priority or a kind of necessity in developing the business communication, however, the moral fitness makes the communication rationally and intentionally fit into the background of a corporation in which it is performed by a professional. What we mean by the background is not an ordinary notion but is a comprehensive idea that includes both rational and intentional capacities which are sufficient conditions for a competent communicative deliberation. Having a sense of language precisely the business linguistic sense when a professional deliberate with moral fitness then s/he qualifies both the necessary and sufficient conditions of a competent business communication. Besides, when a professional really performs a competent business communication s/he actually holds what we call the background intentionality (Corporate Grounded Intentionality) (French: 1982). The two basic elements of background intentionality are: 1) Corporate Moral Personhood (CMP) (Scruton: 1983) and Corporate Epistemic Structure (CES). Business corporations are collective social institutions having a collective moral space where professionals have not only to perform but also have to bear in their minds the corporate policies, rules and basic decisional structure (CID) (French, 1979). However, for qualifying morally to have an effective business communication at par business linguistic sense, a professional has to acquire corporate intentionality so to understand the exercise of corporate personality in his communicative performance. Thus, we need to explain how the moral space is being created under which the corporate intentionality and personality get their shaping. Let's move further to understand CES and CMP in detail to grasp the idea of moral fitness and the background intentionality.

\subsection{Collective Moral Space (CMP): The Connective Ground}

Every rational individual person has certain moral commitments in terms of which his or her intentions and actions are regulated. As such a person, we have a moral personality with a moral space within which I exercise my reasons and decisions in order to actualize our moral intentions. This is our subjective moral space in so far as we traverse this space with the aim of attaining our own development in terms of freedom and dignity. This subjective moral space defines our individual moral personality. Within this moral space my independent existence as an individual is allowed to flourish in whatever manner we choose to do so.

However, as a rational moral person we also extend our moral space beyond its narrow subjective boundary into a social world of fellow human beings. Our basic moral commitments then concern others' welfare, or their freedom and dignity. We enter into a collective space and exercise our causal capacities in such a way that our 
earlier subjective personal agency transforms into the objective agency of a person essentially connected with other persons. In this transformation we end up developing a collective moral space within ourselves. Our movement within this public or collective space is then governed by shared beliefs, shared desires and shared intentions all regulated by shared goals and values.

What we want to argue here is that our ability to participate in a collective corporate framework is dependent on the possibility of our individual subjective moral space into an objective space of collective moral consciousness. We must cultivate a moral self-development by imbibing the spirit of institutional values and committing ourselves to institutional roles and obligations as a responsible agent. A collective moral personality develops with collective corporate desires and intentions and values, all amounting to living a life of corporate culture.

The collective moral space is an objective space where we realize objective moral obligations. Causally we are completely connected with our moral emotions by virtue of first-personal point of view that defines our individual existence. But our entry into the collective space of social life involves the experience of moral emotions that are anchored in the third-personal perspective. Collective beliefs and values, policies and rules, interests and goals constitute a lived space, in which collective intentions are translated into corporate actions. And the experience of collective desires and intentions from the third-personal perspective provide a moral tutelage to our first-personal causal capacities (Note 1).

In a corporate framework, we follow those corporate codes of conduct which are not created by our own desires, and they are not first-personal in the sense that they are not our subjective desires. The corporate codes of conduct are accepted by us from the third-personal point of view of collective desires, intentions and goals. In the light of these common desires, intentions and goals, we develop what Pettit calls action-suited beliefs which further guide our causal capacities in a collective framework (Note 2).

As such, we are governed by what French calls "collective internal decision structure" (CID) in a collective corporate framework. CID is the part of corporate epistemic structure (CES) and constitution that underpins the collective moral space. The development of a collective moral personality is a testimony to the extension of our moral space from the individual level to the collective level of life.

\subsection{Corporate Internal Decision Structure (CID) and Corporate Epistemic Structure (CES)}

French (1979) argues that corporate internal decision structure (CID) is a "re-description intentionality device" that explains the collective intentions of corporations (Note 3). Corporate intentions follow from corporate values, policies and rules. And, in a corporation, roles and responsibilities of persons are administrated by corporate intentions. What French means by this argument is that although individuals have their personal intentions in corporations, corporate intentions differ from their personal intentions. Thus, individuals' actions in a collective corporate framework can be explained only through understanding the corporate intentions. In this way, in a corporate framework, we can explain the member persons' intentions only through CID.

In my consideration, French's notion of CID is the part of CES that governs individuals in a collective corporate framework. The CES both sustains and explains the purpose of corporate actions. In the general context, individual persons are moral agents in virtue of the fact that the causal capacity of their embodied agency is exercised under the regulation and governance of certain epistemic principles. Indeed, their moral agency is structured and shaped by these principles and structures. Thus, any moral action on the part of an embodied agent is explained by reference to embodied causal capacity on the one hand and guidance by a set of epistemic principles on the other.

In the corporate context, it looks a bit unclear how we can attribute corporate actions to what we have called a corporate person or corporate agency. If a corporation is a metaphysical entity and not an individual existent, then it is clear that we cannot ascribe embodied agency to it of the kind which accounts for the causal capacity of individual agents. What, then, warrants our talk of corporate persons and intentions and execution of actions towards corporate goals? How does one provide a satisfactory answer to this question?

The answer that we try to provide here refers to the complex combination between the individual members of a corporation on the one hand, and the CES underlying CID on the other hand. It is true that the exercise of causal agency of the individual members governed by their subjective or personal epistemic structure (PES) will not account for corporate actions. Also, the CES that underlies CID of a corporation provides only the necessary condition for corporate action. The sufficient condition requires that there be a causally adequate agency to bring about such actions. Obviously, corporate agency will have to be captured in terms of the agency of the embodied causal agents, i.e. the individual members constituting corporation. But these members can collectively constitute the required corporate agency only when the CES underlying CID appropriately govern their 
individual causal powers.

In a corporate framework, what is right and what is wrong is decided by what Goodpaster \& Matthews calls "corporate conscience". A corporation has a conscience not in that sense that it has the capacity to make right or wrong choices. Rather, corporate conscience consists in the moral choices made by the constituent members in the light of the relevant CES. While corporate conscience can be said causally to reside in member individuals, the guiding principle that regulates that causal capacity issues from the CES that underlies the CID of corporation.

Thus it is CES which provides an explanation of the purpose of corporate action. In a collective corporate framework, it is CID that explains the corporate actions. And individuals are administrated by CID. Pettit argues that in groups individuals develop action-suited belief systems to perform collective tasks. When we look into the collective corporate framework, we find that the CES provides that action-suited belief system to individuals. And the individuals coordinate themselves in togetherness and collectively execute corporate tasks in an organized manner.

What I have argued for thus far is that the collective moral space that persons create in a collective corporate framework is embedded in corporate CES, which is not reducible to PES, that is, the beliefs, values and intentions of the individual members of corporation. And a corporate moral personality is metaphysically underpinned by the CES of corporation concerned. Therefore, in a corporate framework, it is corporate personhood that provides an explanation of the moral behavior of the member individuals. Furthermore, it is corporate personhood which is decisive in the functioning of a corporation. However, the primacy and decisiveness of corporate personhood is not such as to confiscate the moral agency of the individuals. Rather, the moral agency of the individual members of corporation is made to operate in such a way that it becomes the agency of a corporate moral personality instead of remaining as the subjective agency of an individual.

\section{Competent Business Communication: Ethics in Communication}

So far we have argued and explained the business linguistic condition and the moral fitness conditions in order to understand what suffices or makes a communication in corporate or business context befitting as competent to make business a successful enterprise. Collective moral space we just discussed in the above section is the bedrock for business linguistic communication. In the collective moral space professionals develop a collective sense of communication through which they organize and relate to one another. Besides, to this point begins a business life for a professional who has to communicate in corporate context. In other words, going apart from the subjective life a competent business communication has to be performed in a collective space. Thus, business communication is by its very nature a collective communicative performance. Corporate epistemic structure as we have construed is an objective structure, not independent of but separate from individual subjective structure, that a professional has to acquire in order to be a fitting candidate for competent communication. CES underlies collective corporate personality; however, corporate personality underlies the business linguistic sense. Consequently, when we refer to someone as competent in communicating in business context we presuppose that the professional possesses CES that underlies both business linguistic sense and corporate moral personality.

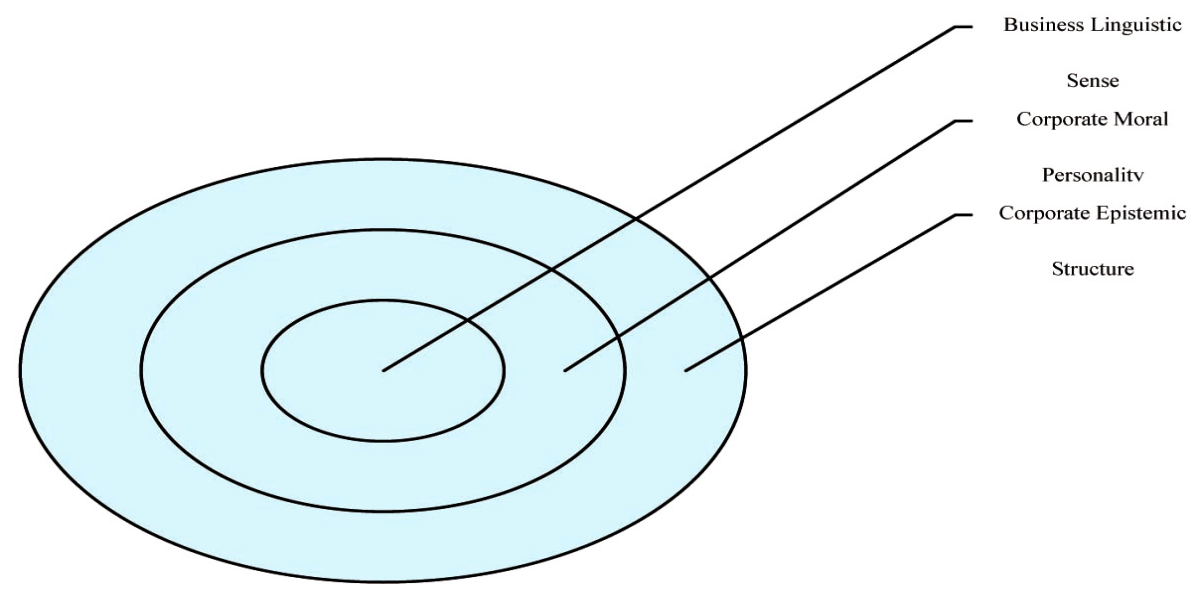

Figure 2. Corporate personality 
Now, it is very much clear that competent business communication is being performed in a peculiar background intentionality that inhere CES. When a professional communicate within the background s/he qualifies as competent business communicator. Intentionality as we know involves a comprehensive knowledge of an object, event, action or performance. CES functions as epistemic device for a professional who takes a communicative stance in a corporation, and thereby against the background of CES a professional develops background intentionality. This development suffices a professional, who is already having the business linguistic sense, to communicate in business context competently and effectively. Before we go to demonstrate how possessing CES makes a professional competent in business or corporate context we would like discuss the crucial role of ethics in making a communicative performance competent.

Ethics in communication we are going to explain is having a normative core and this normative core is intrinsically intertwined with CES. Having business linguistic sense simply means to have first order understanding of cultural-anthropological milieu coupled with socio-psychological character traits of people to whom we business with or cooperate in business or corporate context. Given that business context may be global or multicultural, a professional may or may not be belonging to this background. So keeping this uncertainty in mind we have to have a second order understanding of business linguistic, and this second order understanding is the ethical understanding of moral relativism that is based on cultural relativism. Across the globe live the countless number of cultures having countless number of various morals, rules, ritual, and character traits. Thus, a competent business professional has to acquire not only the first order knowledge of business linguistics but also has to develop the second order normative ethical attitude towards people or society with whom they work. In developing the ethical attitude one has to undergo a neutral space where s/he can seize all bias for any particular value system and can make a sense of respect for every legitimate value system functioning in business or corporate context. After developing the normative sense of respect to the value system to the culture we come to next level of developing a sense of trust and care to the people, company or person we deal with in business context. Without having developed the sense of trust and care we neither take other party in confidence to have a competent communication nor can we extract sufficient information to make communication successful.

Further, developing this normative ethical attitude as an effect possessing a sense of respect, trust and care, however, we have to make this ethical attitude immune to any kind of undue (unreasonable) differences like cast, gender, community, etc... This ethical attitude one must carry with business linguistic sense, however, ethics has a crucial role further to play when it comes to moral qualification for competent business communication, i.e. the development of collective responsibility against the background of collective intentionality rooted in CES. Passing out the moral fitness as we have explained requires acquiring the sense of CES and developing a performative communicative stance against the background intentionality. Albeit acquisition of CES makes a professional competent, ethical attitude holding the sense of collective responsibility gives an effective mode to our business communication. The sense of collective responsibility involves a personal attachment, a fusion of respect, care and trust to a corporation to which we work for. This is what we can call a competent moral participation of a professional in making business communications. And s/he holds a moral personality with a sense of collective responsibility.

Let's demonstrate how CES not only provides a comprehensive business linguistic knowledge but also a moral tutelage to a professional to make a business communication competent and effective. Let's take Indian business scenario where a Japanese professional has to lead a communication while working in a Multinational Corporation. Now s/he has to work in Indian systems and has to first acquire business linguistics in learning the cultural-anthropological milieu and socio-psychological character traits (meta-structure of language beneath the grammatical structure) with having a normative ethical attitude so that he can better understand the effective strategies to deal with the people of India. Besides, s/he has to work in collective moral space and carry the collective corporate personality in a way coordinating with the values, morals, norms, and action suited believes that a corporation holds as a matter of collective participation and deliberation.

Here, it is worthwhile mentioning that the CES that underlies both BLS (Business Linguistic Sense) and Corporate Personality operate in an ethical manner. And, it is in this way CES by comprehensively proving the background intentionality also brings ethics in communication. Therefore, a Japanese professional has to acquire CES coupled with ethical attitude in deliberating and communicating in a business context. In other words, s/he has to acquire a moral personality having sense of CES and an ethical attitude to deal with the people of different communities and culture. Indeed s/he has to have a good knowledge of language in have a good grammatical sense and this is what we call having just a communicative sense but as we have been argued that the just sense is not the competent sense of business communication. Thus, s/he has to develop the competent business 
communication by having recourse to CES and moral personality having a personal relation to a corporation and the people s/he works for. Therefore, a competent business communication involves CES and moral personality having a sense of collective responsibility.

Qualifying the BLC and MC by acquiring CES and corporate moral personality a professional works in collective moral space and against the background intentionality and s/he finds herself or himself intentionally ( culturally, socially, psychologically and morally) attached with a corporation and this so deep and thorough involvement of a professional with a sense of collective responsibility actually qualifies all the necessary and sufficient conditions to perform a competent business communication. It is quite explicit fact if we just try to observe those professional who are having competence in business communication we will see that those professional really personified the conditions we have analyzed and explained so far.

\section{Conclusion}

Words 'bite like a saw into white pine' (Note 4). An exchange of views results in drastic change in one's life or may not result in any change. Writers at least as far back as Aristotle have been struggling with those questions. One thing virtually all of them agree on is that any communicator does have a responsibility toward those with whom he or she communicates (Note 5). The present paper focusses on the nature and place of ethics in current business communicative event. It substantiates that the professionals have to qualify the necessary conditions of Business Linguistic and Moral Fitness. The paper by thoroughly researching on the idea of business communication, proposes a moral perspective on business communication. Business linguistics results in The Sense of Language underlying socio-cultural rationality and background intentionality. This SOL will finally form the base of Competent Business Communication in a real sense.

\section{References}

Altman, L., \& Taylor, D. A. (1973). Social penetration: The development of interpersonal relationships. New York: Holt, Rinehart \& Winston.

Anscombe, G. E. M. (1957). Intention. Proceedings of the Aristotelian Society, 57, 321-332.

Aristotle. (1932). Rhetoric and the Rhetoric of Aristotle. (trans.) Lane Cooper, New York: Appleton-Century-Crofts.

Ashok, R. K. (1980). Prolegomena to an understanding of semiosis and culture. Central Institute of Indian Languages.

Bandura, A. (2000). Exercise of Human Agency through Collective Efficacy. Current Directions in Psychological Science, 9(3), 75-78. http://dx.doi.org/10.1111/1467-8721.00064

Birdwhistll, R. (1970). Kinesics and context: Essays on Body Motion. Philadelphia: University of Pennsylvania Press.

Blomberg, D. L. (1996). A theory of dual-role effectiveness: Friendship in the workplace. Doctoral Dissertation, University of Denver.

Bois, S. (1966). The art of Awareness: A text book on general Semantics and Epistemic. Dubuque, Iowa: William C. Brown Company.

Cicero. (1897). Cicero on oratory. (trans.) J.S. Watson. Philadelphia: David McKay. I. 26.

Cicero. (1970). Cicero on oratory and orators. Carbondale: Southern Illinois University Press.

Cody, M. D. (2006). The corporation is social institution. Master's Dissertation, University of British Columbia.

Freeman, R. E. (2002). A Stakeholder Theory of The Modern Corporation. In Hartman, P. L. (Ed.), Perspective in Business Ethics (pp. 171-181). New York: McGraw-Hill.

French, P. A. (1979). Corporation as a Moral Person. American Philosophical Quarterly, 16(3), 207-215.

French, P. A. (1982). Crowds and Corporations. American Philosophical Quarterly, 19, $27-77$.

Gandhi, R. (1974). Presuppositions of human communication. Delhi: Oxford University Press.

Hall, E. T. (1970). The silent language. New York: Doubleday and company.

Hayakawa, S. L. (1960). How words change our lives. In R. Thruelsen and J. Kobler (eds.), Adventures of the Mind. New York: Vintage Books.

Hayakawa, S. L., Hayakawa, A. R., \& Robert, M. (1949). Language in thought and action. New York: Harcourt, Brace and Company. 
Johnson, C. I., Blomberg, D. L., \& Curran, C. E. (1997). Psychology of communication. MA: Simon \& Schuster custom publishing.

Kelkar, Ashok, R. (1964). A Re-examination of some of the fundamental properties of language. Indian Linguistics, 25, 83-92.

Langsdorf, L. (1994). Why Phenomenology in communication research? Human Studies, 17, 1-8. http://dx.doi.org/10.1007/BF01322763

Muir, F. L. (1964). An exploratory factor analysis of psycho-diagnostic and case study information from children in special education classes for the educable mentally retarded. Unpublished Doctoral Dissertation, University of Denver.

Pettit, P. (2007). Responsibility Incorporated. Ethics, 117, 171-201. http://dx.doi.org/10.1086/510695

Scruton, R. (1989). Corporate Persons. Proceedings of the Aristotelian Society, 63, 239-274.

Slifka, S. A. (1969). The value of auto conditioning in the treatment of reticence. Unpublished master thesis. Washington state university.

Vygotsky, L. (1967). Thoughts and Language. Cambridge, MA: MIT Press.

Wendall, J. (1972). Living with Change: The Semantics of Coping. New York: Harper and Row.

Wendell, J. (1946). People in Quandaries. New York: Harper and Brothers.

Wood, J. T. (1995). Relational Communication. Belmont, CA: Wadsworth.

Wood, J. T. (2007). Interpersonal Communication: Everyday Encounters. MA: Wadsworth Cengage Learning.

\section{Notes}

Note 1. A. Bandura (2000) develops an interesting view on collective agency. He argues that the "perceived collective Efficacy" enhances groups' motivational commitment to their missions, resilience to adversity and performance accomplishments".

Note 2. Phillip Pettit (2007), p. 178.

Note 3. p. 94.

Note 4. William Stafford, "Lit Instructor," in Traveling Through the Dark (New York: Harper \& Row Publishers, Inc., 1967), p. 38.

Note 5. See such sources as the following: Henry N. Weiman and Otis Walter, “ Toward an Analysis of Ethics for Rhetoric," Quaterly Journal of Speech, 43 (1957), 266-270; Karl Wallace, "An Ethical Basis of Communication," The Speech Teacher, 4 (1955), 1-9; Frank Iyn S. Haiman, "A Re-examination of the Ethics of Persuasion," Central States Speech Journal, 3 (1952), 5-10; Lane Cooper, The Rhetoric of Aristotle (New York: Appleton, 1932). 